\title{
Olumsuz Yaşam Olayları, Psikolojik Danışma Hizmeti Alma, Ruminasyon ve Stres Arasındaki İlișki
}

\begin{tabular}{lccc}
\hline MAKALE TÜRÜ & Başvuru Tarihi & Kabul Tarihi & Erken Görünüm Tarihi \\
Araştırma Makalesi & 21.05 .2018 & 05.07 .2018 & 06.07 .2018 \\
\hline
\end{tabular}

İdil Aksöz Efe iD 1

Atatürk Üniversitesi

Öz

$\mathrm{Bu}$ araștırma, üniversite öğrencilerinin stres düzeylerini, olumsuz yaşam olayları, ruminasyon ve cinsiyet değişkenleri açısından incelemektedir. Araştırmaya 184'ü (\% 59.2) kadın, 127'si (\% 40.8) erkek, toplam 311 üniversite öğrencisi katılmıştır. Yaş ortalaması $21.47(S S=2.09)$, belirtilen ortalama olumsuz yaşam olayı sayısı ise $2.66(S S=1.60)$ olan çalışma grubunda, cinsiyet, olumsuz yaşam olaylarının sayısı, psikolojik danışma hizmeti alma ve ruminasyonun algılanan stres üzerindeki etkisini incelemek için çoklu hiyerarşik regresyon analizi yapılması planlanmış, ancak psikolojik danışma hizmeti alan yeterli sayıda katılımcıya ulaşılamaması nedeniyle bu değişken dahil edilmeyerek analiz yapılmıştır. Sonuçlar, modelin anlamlı olduğunu ve toplam varyansın \% 34'ünü açıkladığını göstermiştir. İlk adımda, cinsiyet ve olumsuz yaşam olaylarının sayısı, algılanan stresin anlamlı yordayıcıları olarak bulunmuştur $\left(R^{2}=.09, F_{(2,308)}=15.13, p<.001\right)$. İkinci adımda modele eklenen ruminasyonun da algilanan stresin anlamlı yordayıcısı olduğu bulunmuştur $\left(R^{2}=.25, F_{(1,307)}=51.46, p<.001\right)$. Çalışmanın bulguları stres düzeyini belirlemeye yönelik cinsiyet, ruminasyon ve olumsuz yaşam olaylarının sayısı gibi kişisel etmenlerin önemini vurgulaması açısından önemlidir. Üniversite öğrencileri ile çalıșan ruh sağlığı uzmanlarının kadın olmanın, daha fazla olumsuz yașam olayı deneyimlemenin ve ruminasyona yatkınlığın, stres düzeyinin artması için risk etmenleri olduğunu göz önünde bulundurmaları önerilebilir.

Anahtar sözcükler: Üniversite öğrencileri, olumsuz yaşam olayları, algılanan stres, ruminasyon, psikolojik danışma.

\footnotetext{
${ }^{1}$ Sorumlu Yazar: Dr. Öğr. Üyesi, Kazım Karabekir Eğitim Fakültesi, Eğitim Bilimleri Bölümü, Rehberlik ve Psikolojik Danışmanlık Anabilim Dalı, E-posta: aksoz.efe@ atauni.edu.tr, https://orcid.org/0000-00015674-957X
} 
Üniversite öğrencilerinin içinde bulundukları yaş dönemi, gelişimsel özellikleri açısından ailelerinden ilk kez ayrılıp kendi bağımsız kimliklerini oluşturmaya çalıştıkları bir süreci kapsamaktadır. Bu süreç içerisinde akademik sorunlar ve uyum sorunlarının yanı sıra ekonomik krizler, doğal afet ve terör olayları, yas süreçleri gibi birçok travmatik sayılabilecek olumsuz yaşam olayının etkisi altında kalan gençler doğal olarak, sosyal ve psikolojik desteğe gereksinim duyabilmektedir. Üniversite öğrencilerinin psikolojik gereksinimlerinin belirlenmesi onlara uygulanacak uygun önleme ve müdahale çalışmalarının yürütülmesi için önemli bir aşamadır. Alanyazında yer alan çalışmalar üniversite öğrencilerinin oldukça farklı sorunlarla baş etmeye çalıştıklarını göstermektedir. Üniversite öğrencilerinin en sık yaşadıkları psikolojik sorunları belirlemeyi amaçlayan bir çalışmada, Heppner ve diğerleri (1994) bilgisayar programına dayalı bir ölçek kullanarak bir sıralama elde etmişlerdir. Bu sıralamada duygusal sorunlar ilk sırada yer alırken, diğer sıralarda sırasıyla fiziksel sorunlar, kişiler arası sorunlar, intihara ilişkin düşünceler ve madde bağımlılı̆̆ına ilişkin sorunlar yer almıştır. Benzer olarak Erdur-Baker, Aberson, Barrow ve Drapper (2006) çalışmalarında Amerika Birleşik Devletleri'nde yaklaşık 45 farklı üniversitenin psikolojik danışma merkezlerine başvuran üniversite öğrencilerinin psikolojik sorunlarını akademik kaygılar, insanlar arası ilişkiler ve uyum sorunları, depresyon, cinsel kaygılar ve yeme (beslenme) sorunları olarak belirlemiş̧lerdir. Yaşanan bu sorunlarda az da olsa yıldan yıla bir artış olduğuna ilişkin sonuçlara da ulaşılmıştır. Ayrıca bu çalışmada üniversite danışma merkezine başvuran öğrencilerin başvurmayanlara oranla kaygı oranlarının daha yüksek düzeyde olduğu belirlenmiştir (Erdur-Baker vd., 2006). Vernon, Dillon ve Steiner (2008) 202 kadın üniversite öğrencisi ile yaptıkları çalışmada, katılımcıların neredeyse tamamının (\% 90.1) yaşamlarında en az bir kez doğrudan travmatik bir olay yaşadıklarını ortaya çıkarmıştır. Bu çalışmadaki katılımcıların \% 27.3'ü yaşadıkları travmatik olayın ölüm tehdidi içermediğini, \% 25.6'sı kendi yaşamlarını doğrudan tehdit eden bir travmatik olay yaşadıklarını ve \% 47.1'i başkalarının yaşamını tehdit eden bir olay yaşadıklarını belirtmişlerdir. En sık belirtilen travmatik yaşantılar, katılımcıların \% 25'inin bildirdiği motorlu araç kazaları ve \% 17.0 ile ölümcül hastalık ya da yaralanma olarak raporlanmıştır. Olumsuz yaşam olaylarının üniversite öğrencileri arasındaki yaygınlığını belirlemeyi amaçlayan bir başka çalışmada ise Anders, Frazier ve Shallcross (2012) araştırmaya katılan 1084 kişinin \% 89'unun yaşamları boyunca en az bir travmatik olay yaşadıkları, bu olaylar arasında da en sık doğal afetlerin ve ölümcül hastalıkların raporlandığını belirtmişlerdir. $\mathrm{Bu}$ araştırmada katılımcıların ortalama $3.08(S S=2.48)$ olumsuz yaşam olayı raporladıkları ve bu olayların sayısı ile travma sonrası stres bozukluğu ve stres bulgularının pozitif yönde, yaşam doyumu, genel not ortalaması (akademik başarı) ile ruhsal ve fiziksel sağlıkla negatif yönde ilişkili olduğu da bulunmuştur (Anders vd., 2012).

Üniversite öğrencilerinin maruz kaldığı olumsuz yaşam olaylarının neden olduğu olumsuz sonuçları inceleyen Duncan (2000), çocukluk çağı istismarına maruz kalan öğrencilerinin okulu bırakma eğiliminin istismara uğramamış arkadaşlarından daha yüksek olduğunu bulmuştur. Travmatik bir yaşantı geçmişi olan üniversite 
öğrencilerinin, travmatik bir olay yaşamamış öğrencilerden daha yüksek düzeyde depresyon ve kayg1 yaşadıkları da bilinmektedir (Jackson ve Finney, 2002; Vrana ve Lauterbach, 1994). Benzer şekilde, üniversite öğrencilerinin yaşadıkları stres; kaygı düzeyleri (Misra ve McKean, 2000) ve şiddet davranışlarıyla (Gelaye vd., 2008) da ilişkili bulunmuştur. Olumsuz yaşam olaylarının neden olduğu sonuçlar, cinsiyete göre de değişiklik göstermektedir. Kadınların stres ve depresif belirti düzeyleri, birçok araştırmada erkeklerden daha fazla bulunmuştur (Brougham, Zail, Mendoza ve Miller, 2009; Deatherage, Servaty-Seib ve Aksöz, 2014; Frazier vd., 2009; Misra, McKean, West ve Russo, 2000). Kadınların erkeklerden daha incinebilir olduğunu ve duygudurum (mod) bozukluklarına daha fazla eğilimli olduğunu gösteren çalışmalar, erkeklerin olumsuz yaşam olayları karşısında alkol ve madde kullanımı gibi kendilerine zarar vermeye yönelik tepkilerinin daha fazla olduğunu da göstermektedir (Jackson ve Finney, 2002).

Türkiye'de yapılan çalışmalar, üniversite öğrencilerinin fiziksel görünüşlerine ilişkin kaygılar (Cansever, Uzun, Dönmez ve Özşahin, 2003), intihara ilişkin düşünceler ve intihar girişimi (Lester, Castromayor ve İçli, 1991), yüksek oranda sigara tüketimi, yaygın alkol kullanımı, depresyon ve kaygı (Akvardar vd., 2003) gibi sorunlar yaşadığını ortaya koymuştur. Yine Türkiye'de, psikolojik danışma servisine başvuran üniversite öğrencilerinin psikolojik belirtilerini inceleyen bir çalışmada kız öğrencilerin kaygı ve depresyon belirtilerinin, erkek öğrencilerin ise öfke belirtilerinin yüksek olduğu bulunmuştur (Deniz, Avşaroğlu ve Hamarta, 2004). Türkiye’de yapılan bir başka araştırmada ise üniversite öğrencilerinin yaklaşık yarısının (\% 47.0) üniversite çağından önce ve yine yaklaşık yarısının da (\% 49.0) üniversite döneminde bir yakınlarının kaybı ile başa çıkmak zorunda kaldıkları bulunmuştur (Erdur-Baker, Aksöz ve Dolunay, 2009). Yine aynı araştırmada, üniversite öğrencilerinin deneyimledikleri olumsuz yaşam olaylarının sayısı arttıkça yaşadıkları stresin de arttığı görülmüştür (Erdur-Baker, Aksöz ve Dolunay, 2009). Atik ve Yalçın (2011) Türkiye'deki üniversite öğrencileri ile yaptıkları çalışmalarında, öğrencilerin psikolojik destek arama eğilimlerini incelemiş ve erkek öğrencilerin daha az psikolojik yardım aldığını bulmuşlardır. Ayrıca, öğrencilerin yaşadıkları sorunları önce arkadaşlarıyla sonra da aileleri ile paylaşmayı tercih ettikleri, psikolojik danışma hizmeti almanın akraba ve üniversite hocalarıyla paylașmanın ardından tercih edildiği ve katılımcıların \% 87.0'ının kampüste var olan psikolojik danışma hizmetlerinden haberdar olmadığını belirtmesi de çalışmada elde edilen diğer önemli bulgulardır (Atik ve Yalçın, 2011).

Travma yaşantılarının incelendiği bir araştırmada Breslau ve diğerleri (1998), 2181 katılımcının içinde, travmatik deneyimin en sık ortaya çıktığ 1 yaş aralığının 1620 olduğunu bulmuştur. Bu dönemin üniversite öğreniminde yer alan öğrencilerin genel yaş aralığına da denk geldiği söylenebilir. Geleneksel üniversite öğrencisi kavramı için araştırmacılar tarafından 17-22 yaş aralığı (Medalie, 1981) ya da 18-22 yaş aralığı (Pascarella ve Terenzini, 2005) belirtilmektedir. Yaşla paralel olarak üniversite öğrencilerinin, içinde bulundukları gelişimsel dönem ele alındığında da olumsuz yaşam olaylarını deneyimleme ve bunlarla baş etmeye çalışma olasılıklarının 
yüksek olduğu düşünülebilir. Üniversite öğrencilerinin ailelerinden bağımsız olarak yeni bir destek sistemi geliştirdikleri ve yaşamlarına devam edebilmek için deneyimledikleri olumsuz olaylarla baş etmek için yeni yöntemler belirledikleri bilinmektedir (Arnett, 1998; Chickering ve Reisser, 1993). Olumsuz yaşam olaylarıyla başa çıkmak için geliştirdikleri bu yöntemlerin de zamanla değişerek daha başarılı duruma geldiği, üniversiteye yeni başlayan öğrencilerle son sınıf öğrencilerinin stres ve depresyon belirti düzeyleri arasında anlamlı farkl1lıklar olduğunu gösteren bir çalışmada ifade edilmektedir (Jackson ve Finney, 2002). Ancak stresle başa çıkmada kullanılan birçok yöntem arasında bazılarının diğerlerinden daha etkili olduğuna ilişkin bulgular elde edilse de (Schnider, Elhai ve Gray, 2007; Stewart, 1999; Videka-Sherman, 1982), hâlâ stresle baş etme yöntemlerinden hangilerinin nerede ve nasıl kullanıldığı durumda daha etkili olduğu tam olarak bilinmemektedir.

Duygu ve düşünceleri düzenleme, en s1k kullanılan stresle baş etme yöntemleri arasındadır. Yaşanan olumsuz olayların ardından bireylerin duygu ve düşüncelerini düzenlemelerinin stres düzeylerini azalttığı bilinmektedir. Bireylerin ruminasyon tepkileri ve psikolojik destek alıp almamaları, günlük yaşam olaylarına tepkilerini ve bu olayların değerlendirilmesindeki perspektiflerini ve akademik başarısızlık, ekonomik sorunlar ya da boşanma/ ayrılık gibi stres yaratan durumlarla başa çıkma yöntemlerini etkiler. Ruminasyon, genel olarak etkisiz bir başa çıkma yöntemi olarak değerlendirilir ve bireylerin olumsuz duygularıyla başa çıkmak için kendilerine odaklanmaları olarak tanımlanır (Lyubomirsky ve Nolen-Hoeksema, 1995; NolenHoeksema ve Morrow, 1991). Siklıkla kullanılan bu yöntemin etkisiz olarak değerlendirilmesi, yüksek ruminasyon tepkilerinin depresyon (Nolen-Hoeksema ve Morrow, 1991; Treynor, Gonzalez ve Nolen-Hoeksema, 2003) ve yüksek stres düzeyi (Nolen-Hoeksema, Parker ve Larson, 1994) ile ilişkili olduğu bulgularına dayanmaktadır.

Yukarıda özetlenen çalışma bulgularından da görülebileceği gibi, bireylerin yaşadıkları olumsuz yaşam olayları ve zorlayıcı durumlar karşısında algıladıkları stres düzeyinin farklılıkları, bireysel ve sosyal birtakım değişkenlerden etkilenmektedir. Üniversite öğrencilerinin yaşadıkları zorluklarla başa çıkma süreçlerinde ruminasyon tepkilerinin stres düzeyleri ve işlevsellikleri üzerindeki etkisi birçok araştırmada incelenmiştir. Fakat olumsuz yaşam olayları deneyimlerinin, cinsiyet, psikolojik danışma hizmeti alma ve ruminasyon tepkileri ile birlikte algılanan stres düzeylerine etkisini bir arada incelemek önemlidir. Türkiye'de üniversite öğrencilerinin deneyimledikleri olumsuz yaşam olayları ve bu olayların bazı kişisel özelliklerle birlikte stres düzeylerine etkisini inceleyen çalışmaların sayısı yeterli değildir. Özellikle üniversite öğrencileri ile çalışan psikolojik danışmanların ve diğer ruh sağlığı uzmanlarının, öğrencilerin stres düzeylerini ve bu stresi etkileyebilecek bazı etmenleri daha iyi yorumlayabilmeleri için bu değişkenlerin bir arada incelenmesi gereklidir. Bu nedenle bu araştırmanın amacı üniversite öğrencilerinin algıladıkları stres düzeylerini, olumsuz yaşam olayları, psikolojik danışma hizmeti alma, ruminasyon ve cinsiyet değişkenleri açısından inceleyerek alanyazındaki eksikliğin 
giderilmesine yardımcı olmaktır. Bu doğrultuda yanıtları aranan araştırma soruları şunlardır:

1. Üniversite öğrencilerinin zorlu yaşam olayları karşısında algıladıkları stres ne düzeydedir?

2. Üniversite öğrencilerinin deneyimledikleri zorlu yaşam olayları nelerdir ve bu olayların içinde en çok strese neden olan olay nedir?

3. Üniversite öğrencilerinin deneyimledikleri zorlu yaşam olaylarının üzerinden geçen süre ile algıladıkları stres düzeyi arasında bir ilişki var midir?

4. Üniversite öğrencilerinin algıladıkları stres düzeyleri, cinsiyet, olumsuz yaşam olaylarının sayısı, psikolojik destek alma ve ruminasyon düzeyleriyle nasıl yordanmaktadır?

\section{Yöntem}

Bu başlık altında araştırmanın modeli ele alınmış, çalışma grubu tanıtılarak grup hakkında demografik bilgiler özetlenmiş, araştırmada kullanılan veri toplama araçları tanıtılmış ve verilerin analizinde izlenen yol, kullanılan bilgisayar programı, güven aralığı, test edilen sayıltılar, bu sayıltıların sonuçları ve analiz için yapılan diğer işlemler açıklanmıştır.

\section{Araştırma Modeli}

$\mathrm{Bu}$ araştırma nicel bir çalışma olup betimsel bir araştırma olarak tasarlanmıştır ve korelasyonel bir çalışmadır. Araştırmada cinsiyet, olumsuz yaşam olaylarının sayısı, psikolojik danışma hizmeti alma, ruminasyon ve algılanan stres değişkenleri arasındaki ilişkiler incelenmiştir.

\section{Çalışma Grubu}

Gereken etik kurul izinleri alındıktan sonra, üniversite lisans öğrencilerinden oluşan katılımcılara kolayda örnekleme yöntemi ile ulaşılmıştır. Araştırmanın örneklemini Atatürk Üniversitesi'nin farklı sınıf ve bölümlerinde eğitimlerine devam eden, 184'ü (\% 59.2) kadın, 127'si (\% 40.8) erkek, toplam 311 öğrenci oluşturmuştur. Katılımcıların yaş ortalaması $21.47(S S=2.09)$, deneyimlenen ortalama olumsuz yaşam olayı sayısı ise $2.66(S S=1.60)$ olarak bulunmuştur. Araştırmaya katılan öğrencilerden, 16'sı (\% 5.1) yaşadıkları olumsuz olayın ardından psikolojik destek aldığını belirtirken, 268 katılımcı (\% 86.2) psikolojik destek almadığını belirtmiştir. 
Tablo 1.

Katılımcıların Demografik Özellikleri $(N=311)$

\begin{tabular}{|c|c|c|c|}
\hline & & $f$ & $\%$ \\
\hline \multirow{2}{*}{ Cinsiyet } & Kadın & 184 & 59.2 \\
\hline & Erkek & 127 & 40.8 \\
\hline \multirow{3}{*}{ Psikolojik destek } & Evet & 16 & 5.1 \\
\hline & Hayır & 268 & 86.2 \\
\hline & Boş & 27 & 8.7 \\
\hline \multirow{6}{*}{ Sinif } & 1. sinif & 66 & 21.2 \\
\hline & 2. $\sin i f$ & 45 & 14.5 \\
\hline & 3. sinif & 101 & 32.5 \\
\hline & 4. sinif & 69 & 22.2 \\
\hline & 5. sinif* & 5 & 1.6 \\
\hline & Boş & 25 & 8.0 \\
\hline \multirow{6}{*}{ Medeni durum } & Bekar & 241 & 77.5 \\
\hline & Flört & 49 & 15.8 \\
\hline & Nişanlı & 10 & 3.2 \\
\hline & Evli & 7 & 2.3 \\
\hline & Diğer & 1 & .3 \\
\hline & Boş & 3 & 0.9 \\
\hline \multirow{5}{*}{ Çalışma durumu } & Çalışmıyor & 278 & 89.4 \\
\hline & Yarı zamanlı & 17 & 5.5 \\
\hline & Tam zamanlı & 5 & 1.6 \\
\hline & Diğer & 5 & 1.6 \\
\hline & Boş & 6 & 1.9 \\
\hline \multirow{18}{*}{ En stresli olay } & Uyku düzeninde bozukluk & 48 & 15.4 \\
\hline & Partner/ arkadaş/ aile bireyi ile tartışma & 34 & 10.9 \\
\hline & Romantik ilişki ayrılığı/ boşanma & 32 & 10.3 \\
\hline & Bir yakının ağır yaralanması/ hastalık & 28 & 9.0 \\
\hline & Akademik başarısızlık & 26 & 8.4 \\
\hline & Maddi sorunlar/ güçlükler & 23 & 7.4 \\
\hline & Aile baskısı & 11 & 3.5 \\
\hline & Ağır yaralanma/ hastalık & 9 & 2.9 \\
\hline & Travmatik olaya tanık olmak & 9 & 2.9 \\
\hline & Ayrımcilık & 8 & 2.6 \\
\hline & Çevrimiçi (online) taciz/ tehdit & 5 & 1.6 \\
\hline & Tutuklanma & 4 & 1.3 \\
\hline & Cinsel istismar/ taciz & 2 & .7 \\
\hline & Anne-baba boşanmas1/ ayrılığ & 1 & .3 \\
\hline & Suça maruz kalmak & 1 & .3 \\
\hline & Hamilelik/ kürtaj & 1 & .3 \\
\hline & Diğger & 5 & 1.6 \\
\hline & Boş & 64 & 20.6 \\
\hline
\end{tabular}

* Beşinci sınıfa ait veriler Tıp, Diş Hekimliği ve Kazım Karabekir Eğitim Fakültesi’nin bazı bölümleri gibi, 4 yılın üzerinde eğitim süresi olan bölümlerin öğrencilerinden elde edilmiştir. 
Tablo 1'de de görüleceği üzere, araştırmaya katılan öğrencilerin 66's1 (\% 21.2) birinci sınıfta, 45'i (\% 14.5) ikinci sınıfta, 101'i (\% 32.5) üçüncü sınıfta, 69'u (\% 22.2) dördüncü sınıfta, 5’i (\% 1.6) beşinci sınıfta öğrenim görmektedir ve 25 katılımcı (\% 8.0) bu soruyu yanıtlamamıştır. Yine Tablo 1'de görüleceği gibi, en çok strese neden olan olumsuz yaşam olayı olarak en fazla raporladıkları olay $(n=48, \% 15.4)$ uyku düzenindeki bozukluktur. Bu olayı sırasıyla partner/ arkadaş/ aile bireyleriyle tartışma ( $n=34, \% 10.9)$, romantik ilişki ayrılığı/ boşanma $(n=32, \% 10.3)$, bir yakının ağır yaralanması/ hastalığı $(n=28, \% 9.0)$, akademik başarısızlık $(n=26, \% 8.4)$, maddi sorunlar $(n=23, \% 7.3)$, aile baskısı $(n=11, \% 3.5)$, ağır yaralanma/ hastalık $(n=9$, $\% 2.9)$, travmatik olaya tanık olma $(n=9, \% 2.9)$, ayrımcılık $(n=8, \% 2.6)$, çevrimiçi (online) taciz/ tehdit $(n=5, \% 1.6)$, tutuklanma $(n=4, \% 1.3)$, cinsel istismar/ taciz ( $n=2, \% 0.7)$, anne-babanın boşanması/ ayrılığı $(n=1, \% 0.3)$, suça maruz kalmak $(n=1, \% 0.3)$ ve hamilelik/ kürtaj $(n=1, \% 0.3)$ izlemiştir. Katılımcıların beşi (\% 1.6) diğer stres verici olayları yaşadıklarını belirtirken, 64 katılımcı (\% 20.6) soruyu yanıtlamamıştır.

\section{Veri Toplama Araçları}

Katılımcılara Algılanan Stres Ölçeği, Ruminasyon Ölçeği ile 18 maddelik olumsuz yaşam olayları tarama listesi ve psikolojik danışma hizmeti alıp almadıklarını içeren bir demografik form uygulanmıştır. Algılanan Stres Ölçeği’nin ve Ruminasyon Ölçeği'nin çalışmada kullanılması için gerekli yazar izinleri alınmıştır. $\mathrm{Bu}$ ölçeklerin dışında çalışmaya katılmadan önce tüm katılımcılara "Gönüllü Katılım Formu” ve çalışmayı tamamlayan katılımcılara ayrıca "Katılım Sonrası Bilgi Formu” verilmiştir.

Algılanan stres ölçeği. Cohen, Kamarck ve Mermelstein (1983) tarafindan geliştirilen Algılanan Stres Ölçeği, bireylerin bir aylık zaman dilimi içinde yaşamlarında algıladıkları stresi ölçmeyi amaçlamaktadır. Beşli dereceleme ile ölçülen ve 14, 10 ve 4 maddelik üç ayrı kullanım şekli olan bu ölçeğin, bu çalışmada 10 maddelik formu kullanılmıştır. Cohen, Kamarck ve Mermelstein (1983) tarafindan geliştirilen 10 maddelik yapının güvenirlik katsayısı $\alpha=.86$ olarak verilmiştir. Ölçekten alınan yüksek puanlar, algılanan stresin de yüksek olduğuna işaret etmektedir ve alınabilecek en yüksek puan 50'dir. Ölçeğin Türkçe'ye uyarlamasını Örücü ve Demir (2009) yapmış ve güvenirlik katsayısı Türk örneklem grubu için $\alpha=$ .84 olarak bulunmuştur. Ölçeğin yapı geçerliğini test etmek için Genel Sağlık Ölçeği ile korelasyonu hesaplanmış ve iki ölçek arasındaki korelasyon $r=.61(p<.01)$ olarak bulunmuştur (Örücü ve Demir, 2009). Bu araştırmada ise Algılanan Stres Ölçeği'nin üniversite öğrencileri çalışma grubu için güvenirlik katsayısı $\alpha=.78$ olarak hesaplanmıştır.

Ruminasyon ölçeği. Bireylerin depresif duyguduruma (mod) verdikleri tepkiyi ölçmek amaciyla Nolen-Hoeksema, Parker ve Larson (1994) tarafindan geliştirilmiştir. 22 maddeden oluşan bu ölçekte yanıtlar 4'li derecelendirmeyle değerlendirilmektedir. 22 maddelik bu ilk formdan sonra araştırmacılar birbirine benzeyen maddeleri çıkararak 10 maddeli yeni bir form geliştirmiştir (Treynor vd., 
2003). Ruminasyon Ölçeği’nin bu kısa formu "derinlemesine düşünme" ve "yansıtma" olarak adlandırılan iki alt boyuttan oluşmaktadır. Ölçeğin 10 maddeli yapısı, iki faktörlü ya da tek faktörlü olarak kullanılabilmektedir. On maddelik kısa formun Türkçe'ye uyarlaması Erdur-Baker ve Bugay (2012) tarafindan yapıllmıştır ve her iki yapı da (tek boyutlu ve iki boyutlu) doğrulanmıştır. İki boyutlu yapıda "derinlemesine düşünme" alt boyutunun güvenirlik katsayısı $\alpha=.77$ olarak hesaplanırken, "yansıtma" alt boyutunun $\alpha=.75$ olarak bulunmuştur. Ölçeğin tek boyutlu yapısının güvenirliği ise $\alpha=.85$ olarak raporlanmıştır. Türkçe'ye uyarlama çalışmasında Ruminasyon Ölçeği'nin yakınsak geçerliğini test etmek için Beck Depresyon Envanteri ile arasındaki korelasyon hesaplanmış ve yüksek korelasyon $(r$ $=.60, p<.01$ ) bulunmuştur (Erdur-Baker ve Bugay, 2012). Böylece ölçeğin Türkçe formunun geçerli ve güvenilir bir ölçme aracı olduğu sonucuna varılmıştır.

$\mathrm{Bu}$ araştırmada tek boyutlu yapının üniversite öğrencileri için güvenirlik katsayıs1 $\alpha=.86$ olarak hesaplanırken, iki boyutlu yapıda güvenirlik katsayıları derinlemesine düşünme alt boyutu için $\alpha=.76$ ve yansitma alt boyutu için $\alpha=.78$ olarak bulunmuştur. Tek boyutlu ve iki boyutlu yapıların hem orijinal ölçek için hem de Türkçe formu için doğrulanması ve mevcut çalışmada tek boyutlu yapıda güvenirlik katsayısının daha yüksek hesaplanması nedeniyle analizlere tek boyutlu yapı üzerinden devam edilmiştir.

Demografik form. Katılımcıların yaş, cinsiyet, medeni durum, psikolojik danışma hizmeti alıp almadıkları gibi kişisel bilgilerini sorgulayan bir demografik bilgi formu kullanılmıştır. Demografik formun içinde ayrıca katılımcıların yaşadıkları olumsuz olayları belirlemek amacıyla araştırmacı tarafından 18 maddelik bir kontrol listesi hazırlanmıştır. Katılımcıların, ebeveynlerin boşanması, sevilen birinin kaybı, ağır hastalık/ yaralanma, tutuklanma, zorbalık, akademik başarısızlık, ekonomik sorunlar ve aile içi çatışmalar gibi çeşitli olumsuz yaşam olayları içeren listeden, son üç yıl içinde deneyimlediklerini işaretlemeleri istenmiştir. İşaretlenen yaşam olaylarının toplam sayısı üzerinden değerlendirilen listede yüksek puanlar daha fazla olumsuz yaşam olayına işaret etmektedir.

$\mathrm{Bu}$ formla aynı zamanda katılımcıların işaretledikleri olumsuz yaşam olayları arasında kendileri için en çok strese neden olan olay ve bu olaylara ilişkin profesyonel psikolojik destek alma durumları da sorulmuştur.

\section{Verilerin Analizi}

Çalışmada toplanan verilerin analizi için SPSS (The Statistical Package for The Social Sciences) bilgisayar programı kullanılmış ve güven aralığı $.95(p=.05)$ ve .99 $(p=.01)$ olarak alınmıştır. Bu güvenirlik düzeyleri sosyal bilimler alanında sıklıkla kullanılmaktadır ve araştırma bulgularının, örneklemin ortalama değerlerinin içinde olma olasılığının gücünü gösterir (Fraenkel, Wallen ve Hyun, 2012). Ayrıca, güven aralığının .95 'ten .99'a arttırılması ile tahminin doğruluğuna olan güven de arttığı için (Gravetter ve Wallnau, 2013) çalışma kapsamında bu kriterlerden her ikisi de kullanılmış, $p=.01$ düzeyinde manidar olan değerler özellikle belirtilmiştir. 
Veri toplama sürecinde kullanılan ölçeklerin güvenirlikleri sınanmış ve yapılan bağımsız gruplar $t$-testi ve hiyerarşik regresyon analizleri için gerekli sayıltılar (grup varyanslarının eşitliği, uç değerler, normallik, doğrusallık, eşdeğişkenlilik ve çoklu doğrusallık) kontrol edilmiştir. Grup varyanslarının eşitliği için hem ruminasyon değişkeni hem de algılanan stres değişkeni, cinsiyete göre hesaplanmış ve her iki analizde de Levene's test sonuçlarının anlamsız olduğu görülmüştür. Bu sonuçlar da ruminasyon ve algılanan stres sonuçlarının cinsiyet grupları arasında anlamlı bir farklılığının olmadığını yani varyanslarının eşit olduğunu göstermektedir. Verilerin uç değer içermediği, hesaplanan $z$-değerleri ve Mahalanobis uzaklık değerleri ile tespit edilmiştir. Yapılan incelemelerde z-değerlerinin \pm 3.29 'un altında olması ve serbestlik derecesi $(d f=2)$ için Mahalanobis uzaklık değerlerinin $\chi^{2}=13.816$ değerinin altında olması gerekmektedir (Tabachnick ve Fidell, 2007). Çalışmada verilerin bu değerler arasında olduğu ve uç değer içermediği saptanmıştır. Normallik sayıltısını test etmek için tüm değişkenlerin histogram, Q-Q plot ve boxplot incelemeleri yapılmış ve bu incelemelerde normal dağılım olduğu belirlenmiştir. Ayrıca normal dağılım için analizdeki değişkenlerin çarpıklık ve basıklık katsayılarının sıfira yakın olması gerekmektedir (Tabachnick ve Fidell, 2007). Çalışmada hesaplanan çarpıklık ve basıklık katsayılarının sıfıra yakın olması, bu değerlerin normal dağılıma işaret ettiğini göstermektedir. Artık değerlerin (residuals) doğrusallığ 1 ve eşdeğişkenliliği de histogram, scatterplot ve normal P-P plotlar ve kısmi regresyon grafikleri ile incelenmiş ve bu sayıltıların da sağlandığı gözlenmiştir. Çoklu doğrusallık sayıltısını test etmek için Tabachnick ve Fidell'in önerisi doğrultusunda (2007) analize dahil edilen değişkenler arasındaki korelasyon hesaplanmış ve bu hesaplama sonucu .90 ve üzerinde korelasyonun olmaması nedeniyle bu sayıltının sağlandığı sonucuna varılmıştır. Ayrıca, değişkenlerin tolerans ve VIF değerleri kontrol edilmiş, tolerans değerlerinin .10'dan büyük olması ve VIF değerlerinin 10'un altında olması nedeniyle çalışmada kullanılan değişkenlerin çoklu doğrusallık sayıltısını sağladığı saptanmıştır.

Daha sonra elde edilen bulgulara göre üniversite öğrencilerinin ruminasyon tepkilerinin stres düzeyleri ile ilişkisi, cinsiyet, olumsuz yaşam olayları deneyimleri ve psikolojik danışma hizmeti alma durumları bağlamında incelenmiştir. Field'a (2009) göre "hiyerarşik regresyon analizinde değişkenler önceki çalışma bulgularına dayanarak ve araştırmacının kararına bağlı olarak modele eklenir. Önceki çalışmalarda etkisi bilinen yordayıcılar ilk modelde analize eklenirken yeni değişkenler sonraki modellerde eklenebilir" (s. 212). Bu nedenle mevcut çalışmada ilk modelde stres ile ilişkisi bilinen demografik değişkenler analize eklenmiş, ikinci modelde ise ruminasyon değişkeni eklenmiştir. Ayrıca, hiyerarşik regresyonda analize dahil edilen değişkenlerin sürekli değiş̧en ya da iki gruplu kategorik değişken olması gerekmektedir (Field, 2009). Cinsiyet değişkeni de iki gruplu kategorik bir değişken olduğu için analize dahil edilirken başka bir işlem yapılmamıştır. 


\section{Bulgular}

Araştırmanın amacı üniversite öğrencilerinin algıladıkları stres düzeylerini, olumsuz yaşam olayları, psikolojik danışma hizmeti alma, ruminasyon ve cinsiyet değişkenleri açısından incelemektir. Bu amaç doğrultusunda belirlenen dört temel araştırma sorusunun yanıtlarını bulmak için yapılan analizler ve bu analizlerin sonuçları sırasıyla verilmiştir.

Çalışmada yanıt aranan ilk araştırma sorusu üniversite öğrencilerinin zorlu yaşam olayları karşısında algıladıkları stres düzeyini belirlemeye yöneliktir. Bu amaç doğrultusunda katılımcıların algıladıkları stres düzeyinin ortalama puanı hesaplanmış ve sonuçların ortalamanın üzerinde $(M=31.07, S S=5.84)$ olduğu görülmüştür. Algılanan stres düzeyinin cinsiyetler arasında anlamlı bir farkının olup olmadığını test etmek için ilk aşamada bağımsız gruplar $t$-testi (independent samples $t$-test) yapılmıştır. Yapılan $t$-testinin sonuçları kadın katılımcıların stres düzeylerinin $(M=$ 31.72, $S S=5.80)$, erkek katılımcıların stres düzeyinden $(M=30.13, S S=5.80)$ anlaml biçimde yüksek olduğunu göstermiştir $\left(t_{(309)}=2.38, p<.05\right)$. Kadın katılımcıların erkek katılımcılara göre yaşadıkları olumsuz olay sayısı daha az olsa da $\left(M_{\text {kadın }}=2.53\right.$, $\left.S S_{\text {kadın }}=1.34, M_{\text {erkek }}=2.84, S S_{\text {erkek }}=1.91\right)$, cinsiyetler arasında yaşanan olumsuz olayların sayısı açısından anlamlı bir fark bulunamamıştır $\left(t_{(309)}=-1.71, p>.05\right)$. Cinsiyetin ruminasyon ile ilişkisini incelemek için yapılan $t$-testi sonucu da benzer şekilde kadınların ruminasyon ortalamasının $(M=24.48, S S=5.89)$ erkeklerin ortalamasından $(M=23.51, S S=6.16)$ daha yüksek olduğunu, ancak bu farkın anlamlı olmadığını $\left(t_{(309)}=1.407, p>.05\right)$ göstermektedir.

Çalışmada yanıt aranan ikinci araştırma sorusu ise üniversite öğrencilerinin deneyimledikleri zorlu yaşam olaylarının neler olduğu ve bu olayların görülme sıklığının ne düzeyde olduğudur. Bu sorunun yanıtını elde etmek için ortalama değerler ve frekanslar hesaplanmıştır. Katılımcıların ortalama olumsuz yaşam olayı sayısı $2.66(S S=1.60)$ olarak bulunmuştur. Araştırmaya katılan öğrencilerin en çok stres yaşamalarına neden olan olumsuz yaşam olayı uyku düzenindeki bozukluk $(n=$ 48, \% 15.4) olarak belirlenmiştir. Bu olayı sırasıyla partner/ arkadaş/ aile bireyleriyle tartışma $(n=34, \% 10.9)$, romantik ilişki ayrılığı/ boşanma $(n=32, \% 10.3)$, bir yakının ağır yaralanması/ hastalığı $(n=28, \%$ 9.0), akademik başarısızlık $(n=26, \%$ $8.4)$, maddi sorunlar $(n=23, \% 7.3)$, aile baskısı $(n=11, \% 3.5)$, ağır yaralanma/ hastalık $(n=9, \% 2.9)$, travmatik olaya tanık olma $(n=9, \% 2.9)$, ayrımcılık $(n=8$, $\% 2.6)$, çevrimiçi (online) taciz/ tehdit $(n=5, \% 1.6)$, tutuklanma $(n=4, \% 1.3)$, cinsel istismar/ taciz $(n=2, \% 0.6)$, anne-babanın boşanması/ ayrılı̆̆ $(n=1, \% 0.3)$, suça maruz kalmak $(n=1, \% 0.3)$ ve hamilelik/ kürtaj $(n=1, \% 0.3)$ izlemiştir.

Yaşanan olumsuz olayın üzerinden geçen zamanın algılanan stres üzerinde anlamlı bir farklılığa neden olup olmadığı, çalışmada yanıt aranan üçüncü araştırma sorusudur. $\mathrm{Bu}$ sorunun yanıtını görmek için ayrıca bir bağımsız gruplar $t$-testi yapılmış ve son bir yılda olumsuz yaşam olayını raporlayanlar $(n=176)$ ile iki yıl ve daha fazla zaman önce olumsuz yaşam olayı bildirenler $(n=60)$ karşılaştırılmıştır. Bu $t$-testinin sonuçları, olayın üzerinden bir yıl ve daha az zaman geçen grup ile $(M=$ 
$31.45, S S=6.09)$ iki y1l ve daha fazla geçen grup $(M=31.00, S S=5.44)$ arasında algılanan stres düzeyinin anlamlı bir farklılık olmadığını göstermiştir $\left(t_{(234)}=.54, p>\right.$ $.05)$.

Yapılan $t$-testi sonuçlarına göre cinsiyet değișkeninin olumsuz yaşam olaylarının sayısı ile bir arada stres düzeyine etkisini incelemek için analize birlikte eklenmesine karar verilmiştir. $\mathrm{Bu}$ değişkenlerin etkisi kontrol edildikten sonra katılımcıların ruminasyon tepkilerinin de etkisini incelemek için ikinci adımda ruminasyon puanları analize eklenerek hiyerarşik regresyon analizinin modelleri oluşturulmuştur. Çalışmanın dördüncü araştırma sorusunda yer alan psikolojik danışma alma durumu, psikolojik danışma alan $(n=16, \% 5.1)$ ve almayan $(n=268, \% 86.2)$ öğrenciler arasında karşılaştırma yapılabilecek sayıda katılımcıya ulaşılamaması nedeniyle analize dahil edilmemiştir. Asıl analize geçmeden önce değişkenlerin birbirleri ile olan korelasyonları hesaplanarak ön analizler yapılmış ve bu değerler Tablo 2'de verilmiştir.

Tablo 2.

Değişkenler Arasındaki Korelasyon

\begin{tabular}{lccc}
\hline & $\mathbf{1}$ & $\mathbf{2}$ & $\mathbf{3}$ \\
\hline 1. Olumsuz yaşam olayı sayısı & - & & \\
2. Ruminasyon & $.14^{*}$ & - & - \\
3. Algılanan stres & $.25^{* *}$ & $-.54^{* *}$ & - \\
\hline$* p<.05, * * p<.01$ & &
\end{tabular}

Tablo 2'de görüleceği üzere, öğrencilerin deneyimledikleri olumsuz yaşam olayı sayısı ile ruminasyon tepkileri arasında ve algıladıkları stres arasında anlamlı ve pozitif yönlü ilişkiler olduğu bulunmuştur. Ruminasyon tepkileri ile algılanan stres arasındaki ilişki de anlamlı ve pozitif yönlüdür. Bu sonuçlar doğrultusunda yaşanan olumsuz olayların sayısı arttıkça öğrencilerin ruminatif tepkilerinin ve algıladıkları stresin de arttığı söylenebilir. Ayrıca, ruminasyon tepkileri arttıkça algılanan stresin de arttığı sonuçlardan görülmektedir.

Cohen'in (1992) korelasyon değerlerinin büyüklüğü için belirlediği değerlere göre, $r=.10$ küçük, $r=.30$ orta ve $r=.50$ büyük etki göstermektedir (s. 157). Bu ölçütler 1şı̆̆ında değerlendirildiğinde, olumsuz yaşam olaylarının sayısı ile stres düzeyi arasında düşük düzeyde korelasyon değerleri bulunmuş $(r=.25)$ ancak ruminasyon ile olan korelasyonun orta düzeyde olduğu görülmüştür $(r=.54)$. Hiyerarşik regresyon yaparak hem küçük korelasyonlu değişkenlerin hem de bu değişkenler kontrol edildikten sonra daha büyük korelasyonu olan ruminasyonun etkisini görmek amaçlanmıştır. Hiyerarşik regresyon kullanarak her adımda modele eklenen değişkenlerin tek tek açıkladıkları varyans görülebildiği için (Field, 2009) küçük de olsa tüm etkilerin analize dahil edilmesi hedeflenmiştir. 
Sonraki adımda cinsiyet, olumsuz yaşam olaylarının sayısı ve ruminasyonun üniversite öğrencilerinin algıladıkları stres düzeyleri üzerindeki etkisini incelemek için çoklu hiyerarşik regresyon analizi yapılmıştır. İlk basamakta cinsiyet ve olumsuz yaşam olaylarının sayısının algılanan stres düzeyi üzerindeki etkisinin kontrol edilmesinin ardından, ikinci adımda bu değişkenlere ek olarak modele ruminasyonun eklenmesi ile yapılan hiyerarşik regresyon analizinin sonuçları Tablo 3 'te verilmiştir.

Tablo 3.

Algılanan Stres Düzeyini Yordayan Değişkenler

\begin{tabular}{|c|c|c|c|c|c|c|c|c|}
\hline & \multicolumn{8}{|c|}{ Algılanan Stres } \\
\hline & $R^{2}$ değişim & $F_{\text {değişim }}$ & $\boldsymbol{R}_{\text {toplam }}^{2}$ & $F_{\text {toplam }}$ & B & $S E$ & $\beta$ & $t$ \\
\hline Model 1 & & & .09 & $\begin{array}{l}(2,308)= \\
15.13 * *\end{array}$ & & & & \\
\hline Cinsiyet & & & & & -1.90 & .65 & -.16 & $-2.94 *$ \\
\hline $\begin{array}{l}\text { Olumsuz } \\
\text { yaşam olayı } \\
\text { sayısı }\end{array}$ & & & & & .98 & .20 & .27 & $4.91 * *$ \\
\hline Model 2 & .25 & 113.13 & .34 & $\begin{array}{l}(1,307)= \\
51.46^{* *} *\end{array}$ & & & & \\
\hline Cinsiyet & & & & & -1.34 & .59 & -.11 & $-2.40^{*}$ \\
\hline $\begin{array}{l}\text { Olumsuz } \\
\text { yaşam olayı } \\
\text { sayısı }\end{array}$ & & & & & .70 & .17 & .19 & $4.07 * *$ \\
\hline Ruminasyon & & & & & .49 & .05 & .50 & $10.64 * *$ \\
\hline
\end{tabular}

$* p<.05, * * p<.001$

Tablo 3'te görüleceği üzere, model anlamlı bulunmuş ve toplam varyansın \% 34'ünü açıklamıştır. Cinsiyet ve olumsuz yaşam olaylarının sayısının modele eklendiği ilk aşamada modelin anlamlı olduğu $\left(R^{2}=.09, F_{(2,308)}=15.13, p<.001\right)$ ve bu değişkenlerin modeldeki varyansın \% 9'unu açıkladığı görülmüştür. İlk adımdaki değişkenlere tek tek bakıldığında ise cinsiyetin stres düzeyini negatif yönde yordayan anlamlı bir değişken olduğu, yani kadın olmanın yüksek stres düzeyi ile ilişkili olduğu görülmektedir. Olumsuz yaşam olayları sayısının ise stres düzeyini belirlemede pozitif yönde anlamlı yordayıcı olduğu, yani olumsuz yaşam olaylarının sayısının artması ile stres düzeyinin artmasının ilişkili olduğu bulunmuştur.

İkinci adımda ruminasyonun da modele eklenmesiyle bu modelin algilanan stresin anlamlı yordayıcısı olduğu $\left(R^{2}=.34, F_{(1,307)}=51.46, p<.001\right)$ ve ruminasyonun tek başına modeldeki varyansın \% 25'ini açıkladığı görülmüştür. Modelin ikinci adımındaki değişkenler tek tek incelendiğinde, ruminasyonun ve olumsuz yaşam olaylarının sayısının, algılanan stres düzeyini belirlemede pozitif yönde anlamlı yordayıcılar olduğu, cinsiyetin ise negatif yönde anlamlı bir yordayıcı olduğu görülmektedir. Bir diğer deyişle bu bulgular, ruminasyon ve olumsuz yaşam olaylarının artması, algılanan stresin de artacağına ve kadınların erkeklerden daha fazla stres algıladıklarına işaret etmektedir. 


\section{Tartışma, Sonuç ve Öneriler}

$\mathrm{Bu}$ çalışmada üniversite öğrencilerinin algıladıkları stres düzeylerini etkileyen bazı değişkenlerin incelenmesi hedeflenmiştir. $\mathrm{Bu}$ doğrultuda öğrencilerin cinsiyetlerinin, deneyimledikleri olumsuz yaşam olaylarının sayısının ve ruminasyon tepkilerinin, algıladıkları stres üzerindeki etkisi incelenmiştir. Öğrencilerin deneyimledikleri olumsuz yaşam olaylarının ardından psikolojik danışma hizmeti almalarının algıladıkları stres üzerindeki etkisi de incelenmek istenmiş ancak çalışma grubunda bu hizmeti alan ve almayan katılımcıların karşılaştırma yapmaya uygun olmayan düzeyde dengesiz dağılımı nedeniyle bu değişken analiz dışı bırakılmıştır.

Araştırma bulguları öğrencilerin stres düzeylerinin ortalamanın üzerinde olduğunu ve önceki araştırma bulgularına benzer şekilde kadınların erkeklerden daha fazla stres algıladıklarını göstermiştir. Nolen-Hoeksema (2001) bu durumu, kadınların biyolojik olarak duygusallığa yatkınlı̆̆ının, yaşadıkları olaylardan daha olumsuz etkilenmelerine yol açması ile açıklamaktadır. Aynı zamanda kadınların erkeklere kıyasla toplumsal açıdan daha güçsüz olarak algılanmaları, onları stres ve olumsuz yaşam olayları karşısında daha hassas ve kırılgan kılmaktadır (Nolen-Hoeksema, 2001). Benzer şekilde Matud (2004) da kadınların erkeklerden daha fazla stres yaşadığını ve bu farkın özellikle kronik stres ve günlük stres yaşantılarında ön plana çıktığını belirtmiştir. Bu çalışmada da algılanan stres düzeyinin cinsiyetlere göre anlamlı farklılık göstermesi, özellikle kadınların stres düzeylerinin erkeklerden daha yüksek olması, dikkat edilmesi gereken bir bulgudur. Üniversite öğrencilerine psikolojik destek hizmeti sunacak kişilerin, kadınların strese olan yatkınlıklarını göz önünde bulundurması ve müdahale planlarını hazırlarken cinsiyete duyarlı bir yaklaşım sunmaları önerilebilir.

Üniversite öğrencilerinin algıladıkları stres düzeyini belirlemeye yönelik etkisi incelenen bir diğer değişken de olumsuz yaşam olaylarının sayısıdır. Bu çalışmada elde edilen bulgular önceki çalışmaları da destekler şekilde, yaşanan olumsuz olayların sayısı arttıkça stres düzeyinin de pozitif yönde arttı̆̆ını göstermektedir (Anders vd., 2012; Deatherage vd., 2014; Matud, 2004). Ayrıca çalışmada katılımcılar tarafından en çok strese neden olan yaşam olayları olarak belirtilen ilişki sorunları, anne-babanın boşanması, akademik başarısızlık ve maddi sorunlar gibi olayların, üniversite öğrencileri ile çalışan ruh sağlığı uzmanlarının en çok gündeminde olan konular olduğu düşünülebilir. Psikolojik danışmanların bu konulardaki öz-yeterlik düzeylerinin araştırılması ve eksikliklerin giderilmesi için yapılabilecek uygulamaların belirlenmesi, sonraki çalışmalar için önerilebilir. Bunun yanı sıra, Türkiye'de yaşanan çeşitli kriz durumları ve üniversite döneminin ayrıca yaratabileceği stresli koşullar göz önünde bulundurulduğunda, psikolojik danışmanların ve diğer tüm ruh sağlığı çalışanlarının travma ve kriz danışmanlığı konularında daha fazla bilgilendirilmesi ve eğitimler almaları konusunda desteklenmeleri de uygun bir öneri olacaktır.

$\mathrm{Bu}$ çalışmada algılanan stres düzeyi ile ilişkisi incelenen bir diğer değişken ruminasyondur. Ruminasyon, yaşanan olumsuz olaylarla aktif olarak başa çıkmak için 
harekete geçmek yerine içsel süreçlere ve duygulara odaklanmak olarak tanımlanmaktadır (Nolen-Hoeksema, 2000; Nolen-Hoeksema ve Morrow, 1991; Treynor vd., 2003). Ruminasyon tepkilerinin yaşanan olumsuz olay sayısı ile pozitif ilişkili bulunması, bireylerin olumsuz yaşantılarının artmasının ardından daha çok içsel süreçlere dönerek olayları anlamlandırmaya çalışırken başa çıkma yöntemlerinden biri olan ruminasyona başvurmaları ile açıklanabilir. Ruminasyon ile stres arasındaki ilişki de yine önceki çalışmalarda (Nolen-Hoeksema vd., 1994) olduğu gibi, bu çalışmada da pozitif yönde bulunmuş ve ruminasyonun algılanan stresin en yüksek varyansını açıklayan değişken olduğu görülmüştür. Böylece, üniversite öğrencilerinin yaşadıkları stresle başa çıkmada başvurdukları yöntemlerden biri olan ruminasyonun, olumsuz bir etkisinin olduğu söylenebilir. Bu bulgudan hareketle üniversite öğrencilerine psikolojik yardım hizmeti sunan kişilerin dikkat etmesi gereken bir diğer özelliğin, danışanların kullandığı başa çıkma yöntemleri olduğu söylenebilir. Danışanların ruminasyon gibi etkisiz başa çıkma yöntemlerine başvurduğu saptandığında, bu durumun stres ile ilişkisi incelenmeli ve danışanlara daha etkili başa çıkma yöntemleri öğretilmelidir.

Türkiye'de yaşanan terör, doğal afetler ve ekonomik krizler gibi birçok olayın etkisiyle olumsuz yaşam olaylarının ortaya çıkma olasılığı çok yüksek görünmektedir. Üniversite yaşamı da birçok nedenle genç yetişkinler için stres yaratıcı öğeler içerebilmektedir. Üniversite döneminin barındırdığı bu özellikler, olumsuz yaşam olayları ile bir araya geldiğinde bireylerin stresini daha da arttırabilmektedir. Ancak daha önce belirtildiği gibi bireylerin yaşadığı olumsuz yaşam olayları karşısında algıladıkları stres, kullandıkları başa çıkma yöntemleri nedeniyle değişsebilmektedir. Olumsuz yaşam olayları ile karşılaşan her bireyin algıladığı stres düzeyi aynı olmamakta, etkili başa çıkma becerileri olan bireyler, yaşadıkları stresi daha iyi kontrol edebilmektedir. Üniversite öğrencilerinin travmatik yaşantılarına ilişkin uygun müdahale yöntemlerinin belirlenmesi için öncelikle travmatik/ olumsuz yaşantıların ve bireylerin stresle başa çıkma yollarının araştırılması gerekmektedir. Ancak, Türkiye'de üniversite öğrencilerinin olumsuz yaşantılarını ve deneyimledikleri olumsuz olayların stres düzeylerine etkisini inceleyen çalışmaların sayısı yeterli değildir. Özellikle üniversite öğrencileri ile çalışan psikolojik danışmanların ve diğer ruh sağlığı uzmanlarının, bu grubun stres düzeylerini ve bu stresi etkileyebilecek bazı etmenleri daha iyi yorumlayabilmeleri ve uygun müdahale yöntemlerini belirleyebilmeleri için bu değişkenlerin bir arada incelendiği çalışmaların sayısının artması gerekir. Ayrıca, travmatik olaylar karşısında yaşadıkları stresi kontrol etmek için danışma hizmeti almaya gelen bireylere yardım etme konusunda danışmanların daha farklı becerilere sahip olması gerekir (Demirli-Yıldız, Sevil-Gülen ve Erdur-Baker, 2016). Yaşanan olumsuz olayların anlamlandırılması sürecinde psikolojik destek almak isteyen bireylere yönelik verilecek hizmetin niteliğini arttırmak ve ruh sağlığı çalışanlarının bu alanda hizmet vermeye yönelik özyeterliklerini arttırmak için üniversitelerde ruh sağlı̆̆ hizmeti sunan meslek gruplarının eğitim programlarına eklenen dersler ve bu meslek gruplarında çalışan bireylere yönelik çeşitli seminerler, eğitimler vb. yoluyla kriz ve travma konularında 
bilgilendirilmeleri önemlidir. Bu çalışma da travmatik yaşantılara yönelik bir önleme ve müdahale programının geliştirilebilmesi ve gelecek araştırmalara 1şık tutması açısından önem taşımaktadır.

$\mathrm{Bu}$ araştırmada elde edilen önemli bulguların yanı sıra, birtakım sınırlılıklar da bulunmaktadır. Bunların başında psikolojik destek almanın etkisinin incelenmesi için her iki gruptan (psikolojik danışma hizmeti alan ve almayan) yeterli sayıda katılımcıya ulaşılamamış olması gelmektedir. Psikolojik danışma hizmeti almanın, üniversite öğrencilerinin yaşadıkları olumsuz yaşam olaylarının ardından algıladıkları stres düzeyine olan etkisi incelenmek istenmiş ancak gruplar arasında karşılaștırma yapmaya elverişli sayıya ulaşılamamıştır. Bu da psikolojik danışma hizmeti alma değişkeninin analiz dişı tutulmasına neden olmuştur. Ancak önceki çalışmaların da gösterdiği gibi olumsuz/ travmatik olayların ardından psikolojik danışma hizmeti almak bireylerin stresini azaltmaktadır (Erdur-Baker vd., 2006). Sonraki çalışmalarda psikolojik danışma hizmeti almanın etkisini inceleyebilmek ve bu hizmetin etkisinin diğer değişkenlerle ilişkilerini görebilmek için daha dengeli bir katılımcı dağılımına ulaşmak hedeflenmelidir.

$\mathrm{Bu}$ araştırmanın bir diğer sınırlılı̆̆ı da katılımcılara seçkisiz örnekleme yöntemi ile ulaşılmamış olmasıdır. Üniversite öğrencilerinin algıladıkları stres düzeyini etkileyebilecek bazı özellikleri göz önünde bulundurularak tabakalı örnekleme yönteminin kullanılması, farklı sınıf düzeylerinde ve farklı fakültelerde eğitim gören öğrencilere dengeli bir dağılım ile ulaşılmasına olanak sağlayacaktır. Böylece çalışmadan elde edilen bulguların üniversite öğrencilerini temsil etme olasılığı da arttırılmış olacaktır.

Son olarak, bu araştırmanın verilerinin boylamsal desen yerine kesitsel desen ile elde edilmiş olması da bir diğer sınırlılıktır. Aynı örneklem grubu ile belli aralıklarla yeniden çalışılması, üniversite yaşamı boyunca karşılaşılan stresli yaşam olaylarının daha iyi anlaşılmasına da olanak sağlayacaktır. Bu desen ile elde edilecek bilgiler 1şı̆̆ında, üniversitede geçirilen süre ile öğrencilerin denedikleri farklı baş etme yöntemleri olup olmadığ incelenebilir, yıllar içinde öğrencilerin kendilerine daha uygun stratejiler belirlemeleri yönünde neler yaptıkları boylamsal araştırmalar ile ortaya konabilir.

Sonuç olarak, bu araştırmada elde edilen tüm verilerin bir arada incelenmesiyle yaşanan olumsuz olaylarla başa çıkmada kullanılan etkisiz yöntemlerin, algılanan stres düzeyini arttırdığı görülmektedir. Yaşanan olumsuz yaşam olaylarının sayısının artması ve cinsiyetin (kadın olmanın) etkisi ile bir arada ruminasyon tepkilerinin stresi daha fazla yordadığı göz önünde bulundurulduğunda, danışma sürecinde bu bilgilerin dikkatlice ele alınması önerilebilir. 


\section{Kaynakça}

Akvardar, Y., Demiral, Y., Ergör, G., Ergör, A., Bilici, M. ve Özer, Ö. A. (2003). Substance use in a sample of Turkish medical students. Drug and Alcohol Dependence, 72(2), 117-21. doi: 10.1016/S0376-8716(03)00192-3

Anders, S. L., Frazier, P. A. and Shallcross, S. L. (2012). Prevalence and effects of life event exposure among undergraduate and community college students. Journal of Counseling Psychology, 59(3), 449-457. doi: 10.1037/a0027753

Arnett, J. J. (1998). Learning to stand alone: The contemporary American transition to adulthood in cultural and historical context. Human Development, 41(5-6), 295-315. doi: 10.1159/000022591

Atik, G. ve Yalçın, İ. (2011). Help-seeking attitudes of university students: The role of personality traits and demographic factors. South African Journal of Psychology, 41(3), 328-338. doi: 10.1177/008124631104100307

Baqutayan, S. (2011). Stress and social support. Indian Journal of Psychological Medicine, 33(1), 29-34. doi: 10.4103/0253-7176.85392

Breslau, N., Kessler, R. C., Chilcoat, H. D., Schultz, L. R., Davis, G. C. and Andreski, P. (1998). Trauma and PTSD in the community: The 1996 Detroit area survey of trauma. Archives of General Psychiatry, 55(7), 626-632. doi: 10.1001/archpsyc.55.7.626

Brougham, R. R., Zail, C. M., Mendoza, C. M. and Miller, J. R. (2009). Stress, sex differences, and coping strategies among college students. Current Psychology, 28(2), 85-97. doi: 10.1007/s12144-009-9047-0

Cansever, A., Uzun, O., Dönmez, E. ve Özşahin, A. (2003). The prevalance and clinical features of body dysmorphic disorder in college students: A study in a Turkish sample. Comprehensive Psychiatry, 44, 60-64. doi: 10.1053/comp.2003.50010

Chickering, A. W. and Reisser, L. (1993). Education and identity (2. bask1). San Francisco: Jossey-Bass.

Cohen, J. (1992). A power primer. Quantitavite Methods in Psychology, 112(1), 155 159. doi: 10.1037/0033-2909.112.1.155 
Cohen, S., Kamarck, T. and Mermelstein, R. (1983). A global measure of perceived stress. Journal of Health and Social Behavior, 24(4), 385-396. doi: $10.2307 / 2136404$

Crockett, L. J., Iturbide, M. I., Torres-Stone, R. A., McGinley, M. and Raffaelli, M. (2007). Acculturative stress, social support, and coping: Relations to psychological adjustment among Mexican American college students. Cultural Diversity and Ethnic Minority Psychology, 13(4), 347-355. doi: 10.1037/10999809.13.4.347

Deatherage, S., Servaty-Seib, H. L. and Aksoz, I. (2014). Stress, coping, and Internet use of college students. Journal of American College Health, 62(1), 40-46. doi: $10.1080 / 07448481.2013 .843536$.

Demirli-Yıldız, A., Sevil-Gülen, Ö. ve Erdur-Baker, Ö. (2016). Kriz, kriz tepkileri ve kriz danışmanlığı. Kriz danışmanlığı. Ö. Erdur-Baker ve T. Doğan (Ed.), (s. 327). Ankara: Pegem Akademi.

Deniz, M. E., Avşaroğlu S. ve Hamarta, E. (2004). Psikolojik danışma servisine başvuran üniversite öğrencilerinin psikolojik belirti düzeyleri. 13. Ulusal Eğitim Bilimleri Kurultayı, Malatya.

Duncan, R. D. (2000). Childhood maltreatment and college drop-out rates: Implications for child abuse researchers. Journal of Interpersonal Violence, 15(9), 987-995. doi: 10.1177/088626000015009005

Erdur-Baker, Ö., Aberson, C., Barrow, J. and Drapper, M. (2006). Nature and severity of college students' psychological concerns: A comparison of clinical and nonclinical national samples. Professional Psychology: Research and Practice, 37(3), 317-323. doi: 10.1037/0735-7028.37.3.317

Erdur-Baker, Ö., Aksöz, İ. ve Dolunay, F. (2009). Üniversite öğrencilerinin geçmiş travmatik yaşantıları ve şimdiki psikolojik belirtileri (BAP-05-02-2009-02) (Araştırmacı).

Erdur-Baker, Ö. ve Bugay, A. (2012). The Turkish version of the Ruminative Response Scale: An examination of its reliability and validity. The International Journal of Educational and Psychological Assessment, 10(2), 1-16. https://drive.google.com/file/d/0ByxuG44OvRLPbDd1cDVJNnVQbWc adresinden erişilmiştir.

Field, A. (2009). Discovering statistics using SPSS (3. bask1). London: SAGE Publications. 
Fraenkel, J. R., Wallen, N. E. and Hyun, H. H. (2012). How to design and evaluate research in education (8. bask1). New York, NY: McGraw-Hill.

Fraizer, P., Anders, S., Perera, S., Tomich, P., Tennen, H., Park, C. and Tashiro, T. (2009). Traumatic events among undergraduate students: Prevelance and associated symptoms. Journal of Counseling Psychology, 56(3), 450-460. doi: $10.1037 / \mathrm{a} 0016412$

Gelaye, B., Philpart, M., Goshu, M., Berhane, Y., Fitzpatrick, A. and Williams, M. A. (2008). Anger expression, negative life events and violent behavior among male college students in Ethiopia. Scandinavian Journal of Public Health, 36, 538545. doi: $10.1177 / 1403494807086916$

Gravetter, F. J. and Wallnau, L. B. (2013). Statistics for the behavioral sciences (9. bask1). Belmont, CA: Wadsworth.

Heppner, P. P., Kivilighan, D. M., Good, G. E., Roehlke, H. J., Hills H. I. and Ashby, J. S. (1994). Presenting problems of university counseling center clients: A snapshot and multivariate classification scheme. Journal of Counseling Psychology, 41, 315-324.

Jackson, P. B. and Finney, M. (2002). Negative life events and psychological distress among young adults. Social Psychology Quartely, 65(2), 186-201. doi: $10.2307 / 3090100$

Jarama-Alvan, S. L., Belgrave, F. Z. and Zea, M. C. (1996). Stress, social support, and college adjustment among Latino students. Cultural Diversity and Mental Health, 2(3), 193-203. doi: 0.1037//1099-9809.2.3.193

Lester, D., Castromayor, I. J. and İçli, T. (1991). Locus of control, depression and suicidal ideation among American, Philippine and Turkish students. The Journal of Social Psychology, 131, 447-451.

Lyubomirsky, S. and Nolen-Hoeksema, S. (1995). Effects of self-focused rumination on negative thinking and interpersonal problem solving. Journal of Personality and Social Psychology, 69(1), 176-190. doi: 10.1037/0022-3514.69.1.176

Matud, M. P. (2004). Gender differences in stress and coping styles. Personality and Individual Differences, 37, 1401-1415. doi: 10.1016/j.paid.2004.01.010

Medalie, J. (1981). The college years as a mini-life cycle: Developmental tasks and adaptive options. Journal of American College Health Association, 30(2), 7579, doi: 10.1080/07448481.1981.9938882 
Misra, R. and McKean, M. (2000). College students' academic stress and its relation to their anxiety, time management, and leisure satisfaction. American Journal of Health Studies, 16(1), 41-51. https://www.researchgate.net/publication/209835950_College_students'academ ic_stress_and_its_relation_to_their_anxiety_time_management_and_leisure_sa tisfaction adresinden edinilmiştir.

Misra, R., McKean, M., West, S. and Russo, T. (2000). Academic stress of college students: Comparison of student and faculty perceptions. College Student Journal, 34(2), 236-245. doi: 10.1037/1072-5245.11.2.132

Nolen-Hoeksema, S. (2000). The role of rumination in depressive disorders and mixed anxiety/depressive symptoms. Journal of Abnormal Psychology, 109(3), 504511. doi: 10.1037//0021-843X.109.3.504

Nolen-Hoeksema, S. (2001). Gender differences in depression. Current Directions in Psychological Science, 10, 173-176. doi: 10.1111/1467-8721.00142

Nolen-Hoeksema, S. and Morrow, J. (1991). A prospective study of depression and posttraumatic stress symptoms after a natural disaster: The 1989 Loma Prieta earthquake. Journal of Personality and Social Psychology, 61(1), 115-121. doi: 10.1037/0022-3514.61.1.115

Nolen-Hoeksema, S., Parker, L. E. and Larson, J. (1994). Ruminative coping with depressed mood following loss. Journal of Personality and Social Psychology, 67(1), 92-104. doi: 10.1037/0022-3514.67.1.92

Örücü, M. Ç. and Demir, A. (2009). Psychometric evaluation of Perceived Stress Scale for Turkish university students. Stress and Health, 25, 103-109. doi: $10.1002 /$ smi. 1218

Pascarella, E. and Terenzini, P. (2005). How college affects students: A third decade of research. San Francisco: Jossey-Bass.

Schnider, K. R., Elhai, J. D. and Gray, M. J. (2007). Coping style use predicts posttraumatic stress and complicated grief symptom severity among college students reporting a traumatic loss. Journal of Counseling Psychology, 54(3), 344-350. doi: 10.1037/0022-0167.54.3.344

Stewart, A. E. (1999). Complicated bereavement and posttraumatic stress disorder following fatal car crashes: Recommendations for death notification practice. Death Studies, 23, 289-321. doi: 10.1080/074811899200984 
Tabachnick, B. G. and Fidell, L. S. (2007). Using multivariate statistics (5. bask1). Boston, MA: Pearson Educatiin, Inc.

Treynor, W., Gonzalez, R. and Nolen-Hoeksema, S. (2003). Rumination reconsidered: A psychometric analysis. Cognitive Therapy and Research, 27(3), 247-259. doi: 10.1023/A:1023910315561

Vernon, L. L., Dillon, J. M. and Steiner, A. R. W. (2008). Proactive coping, gratitude, and posttraumatic stress disorder in college women. Anxiety, Stress \& Coping, 22(1), 117-127. doi: 10.1080/10615800802203751

Videka-Sherman, L. (1982). Coping with the death of a child: A study over time. American Journal of Orthopsychiatry, 52(4), 688-698. doi: 10.1111/j.19390025.1982.tb01458.x

Vrana, S. and Lauterbach, D. (1994). Prevalence of traumatic events andposttraumatic psychological symptoms in a nonclinical sample of college students. Journal of Traumatic Stress, 7(2), 289-302. doi: 10.1002/jts.2490070209 


\title{
Relations among Negative Life Events, Getting Psychological Help, Rumination and Perceived Stress
}

\begin{tabular}{cccc}
\hline ARTICLE TYPE & Received Date & Accepted Date & Online First Date \\
Research Article & 05.21 .2018 & 07.05 .2018 & 07.06 .2018 \\
\hline
\end{tabular}

İdil Aksöz Efe

Atatürk University

\begin{abstract}
Current study explores the perceived stress level of college students in relation to their gender, number of negative life events (NLE), and ruminative responses. Participants were 311 college students (184 females and 127 males) with a mean age of $21.47(S D=2.09)$. The average of negative life events was $2.66(S D=1.60)$. The effects of gender, number of NLE, use of psychological help and rumination were aimed to be tested by conducting a hierarchical regression analysis. However, since the sample size for the students that use psychological help was not sufficient, this variable was excluded from the analysis. The results showed that the model was significant and explaining $34 \%$ of the variances. In the first step, gender and number of NLE were significant predictors of stress $\left(R^{2}=.09, F_{(2,308)}=15.13, p<.001\right)$. In the second step, rumination was added to the model and found to be a significant predictor of stress $\left(R^{2}=.25\right.$, $\left.F_{(1,307)}=51.46, p<.001\right)$. Results emphasize the personal factors influencing perceived stress such as gender and rumination. Thus, it is suggested for the mental health professionals working with college students to consider these variables while planning their counseling sessions.
\end{abstract}

Keywords: College students, negative life events, perceived stress, rumination, psychological counseling.

\footnotetext{
${ }^{1}$ Corresponding Author: Assistant Professor 1, Kazım Karabekir Faculty of Education, Department of Educational Sciences, E-mail: aksoz.efe@ atauni.edu.tr, https://orcid.org/0000-0001-5674-957X
} 
College life comprises a developmental stage that students get away from their families for the first time in their lives, and develop their identities. This stage usually involves many problems such as academic failures, adaptation issues as well as other traumatic life events such as natural disasters, economic problems, romantic breakups and grief and loss issues. College students, who face with these negative life events, need social and psychological support to cope with their stress caused by these issues. Thus, exploring the psychological needs of college students is an essential step in implementing the appropriate prevention and intervention studies.

Studies in the literature reveal that college students cope with many different life events and problems. In their study, Heppner and colleagues (1994) found that romantic problems was the most frequent issue reported by college students, followed by physical issues, interpersonal issues, suicidal thoughts and drug-related issues respectively. Similarly, Erdur-Baker, Aberson, Barrow, and Drapper (2006) reported that college students in the USA were seeking professional help most frequently for academic concerns, interpersonal relations, adaptation problems, depression, sexual concerns and eating problems. In another study, Vernon, Dillon, and Steiner (2008) revealed that out of 202 female college students, $90.1 \%$ of them experienced at least one traumatic event in their life. The most frequent traumatic event was motor vehicle accidents, followed by serious illness or injury.

Studies exploring the consequences of the traumatic events indicate that students with history of childhood abuse have higher drop-off rates when compared with their peers with no childhood abuse history (Duncan, 2000). Many studies report that students with traumatic event history have higher levels of depression and anxiety (Jackson and Finney, 2002; Vrana and Lauterbach, 1994). Also, there are studies revealing gender differences in terms of the consequences of the traumatic events. For instance, females were found to experience higher levels of stress and depressive symptoms (Brougham, Zail, Mendoza, and Miller, 2009; Deatherage, Servaty-Seib, and Aksöz, 2014; Frazier et al., 2009; Misra, McKean, West, and Russo, 2000), and males were found to be more prone to alcohol and drug abuse (Jackson and Finney, 2002).

Studies in Turkey also show that college students are mostly concerned by their physical appearance (Cansever, Uzun, Dönmez, and Özşahin, 2003), suicidal thoughts and suicide attempts (Lester, Castromayor, and İçli, 1991), high levels of tobacco and alcohol use (Akvardar et al., 2003). Similarly, female students were found to report higher levels of anxiety and depression while male students were reporting higher levels of aggression (Deniz, Avşaroğlu, and Hamarta, 2004).

Individuals facing with negative life events use different methods to cope with these events and stress caused by those events. Some of the coping methods are known to be more effective than others (Schnider, Elhai, and Gray, 2007; Stewart, 1999; Videka-Sherman, 1982), however, individual and situational factors may influence the effectiveness of those coping strategies. Regulating emotions and cognitions is one of the most frequently used coping strategies. It is known that when individuals 
are able to regulate their emotions and cognitions after stressful events, their stress levels are declined. On the other hand, ruminative responses of individuals or not getting professional help may have negative effects on their perspectives while evaluating the adverse events they experience. Rumination, defined as individuals' focusing on themselves to cope with their emotions (Lyubomirsky and NolenHoeksema, 1995; Nolen-Hoeksema and Morrow, 1991), is known to be an unsuccessful coping strategy. Higher levels of rumination were found to be related with depression (Nolen-Hoeksema and Morrow, 1991; Treynor, Gonzalez, and Nolen-Hoeksema, 2003) and higher levels of stress (Nolen-Hoeksema, Parker, and Larson, 1994).

\section{Purpose and Significance}

When individuals experience negative and traumatic life events, their stress level is usually affected by some individual factors such as gender and ruminative response styles. Also, with the help of professional counseling, most individuals cope with their stress better than that who don't get professional help. Thus, this study explores the college students' stress levels when faced with negative life events in relation to their gender and ruminative responses. Findings of the study can provide important insights for mental health professions working with college students.

As summarized above, the differences in the stress levels of individuals' after experiencing negative life events are influenced by some personal and social variables. Several studies explored the relationship between ruminative responses of college students and their stress level or their functionality. However, it is important to explore the negative life events, gender, use of professional help, ruminative responses and perceived stress together. Particularly, it is important for mental health professionals working with college students to understand their experiences in order to find the most suitable prevention and intervention methods. Thus, the current study aimed to fulfill the necessity of the literature by exploring the perceived stress of college students in relation to their gender, negative life events, use of professional help, and ruminative responses. With this purpose, this study explores the answers of the following research questions:

1. What is the level of the stress that college students perceive after experiencing negative life events?

2. What are the negative life events experienced by the college students and which of them is the most stressful event?

3. What is the relationship between the time after the negative life event and perceived stress level of the college students?

4. How the perceived stress level of the college students is predicted by gender, number of negative life events, use of psychological help, and ruminative responses? 


\section{Method}

After gathering the necessary ethical permissions, participants of the current study were recruited via convenience sampling method. The sample consisted of 311 students from Ataturk University. Of the participants, 184 of them (59.2\%) were females and 127 of them (40.8\%) were males. Mean age was $21.47(S D=2.09)$ and the average of negative life events reported by the participants was $2.66(S D=1.60)$.

The design of this descriptive study is correlational. After the data collection procedure, reliability tests were conducted and the assumptions were checked. Since the sample size for the students who used psychological help was too small $(n=16$, $5.1 \%)$ when compared to the students who did not get psychological help $(n=268$, $86.2 \%$ ), the use of psychological help variable was excluded from the study. In the light of the results, relations among college students' gender, number of negative life events, ruminative responses, and perceived stress levels were explored.

In the current study, participants responded to Perceived Stress Scale, Ruminative Responses Scale and a demographic information form including an 18item Negative Life Events Checklist. Apart from these scales, participants were provided with an informed consent form before the study, and a detailed acknowledgement form after the study.

\section{Results}

Before running the analyses, data screenings were done and assumptions were checked. In order to explore the effects of gender, number of negative life events, and ruminative responses on the perceived stress level, a hierarchical multiple regression analysis was conducted. Gender and number of negative life events were controlled in the first step and ruminative response scores of the participants were added in the second step. Results showed that the model was significant overall and explaining $34 \%$ of the variables of the perceived stress. In the first step, gender and number of negative life events were significant predictors, $R^{2}=.09, F_{(2,308)}=15.13, p<.001$, explaining $9 \%$ of the variables in the model. In the second step, after controlling the effects of gender and number of negative life events, ruminative responses was also a significant predictor of perceived stress level, $R^{2}=.25, F_{(1,307)}=51.46, p<.001$, explaining $25 \%$ of the variables in the model.

\section{Discussion and Conclusions}

Findings of the current study revealed that females were experiencing more stress than males, similar to the findings of studies in the literature. Some researchers explain these differences in terms of biological tendencies causing females to be more emotional and prone to experience more adverse effects by the life events (NolenHoeksema, 2001). Similarly, Matud (2004) explains that females experience more chronic and daily life stress than males related to their gender roles and responsibilities. 
Another finding of the current study shows that with higher numbers of negative life events, perceived stress level of the students were getting higher. This finding was also supporting the previous research in the literature, indicating a positive relationship between the number of negative life events and stress level (Anders et al., 2012; Deatherage et al., 2014; Matud, 2004).

Finally, rumination was a significant positive predictor of stress in the current study. This finding was also supporting the previous research, showing that rumination is an ineffective coping strategy (Nolen-Hoeksema, 2000; NolenHoeksema and Morrow, 1991; Treynor et al., 2003). Considering these results together, mental health professionals working with college students should be cautious of their clients' stress levels and causes influencing their stress. Being female and experiencing more negative life events are risk factors for higher levels of stress. Also, use of rumination (i.e., ineffective coping strategies) has a positive relation with stress. Thus, counselors should be looking for stressful events in their clients' lives and understanding the coping strategies that they use.

In conclusion, in a country experiencing many traumatic events such as economic crises, terror and natural disasters, it is not surprising to have higher levels of stress. College life on the other hand, includes its own stressful aspects, which can also influence students' mental health. In order to define appropriate intervention methods specific to college student population, it is important to understand that period's characteristics as well as students' specific life events. This study provides an investigation of negative life events and ruminative responses of college students as factors influencing their stress levels. Results also emphasize the importance of personal factors related with stress level, such as gender, rumination and frequency of adverse life events. Mental health professionals working with college students should consider that being female, experiencing more negative life events and having a ruminative response style are risk factors for stress. 